\title{
Cotreatment with Aspirin and Azole Drugs Increases Sensitivity of Candida albicans in vitro
}

\author{
Wenli Feng \\ Jing Yang \\ Yan Ma \\ Zhiqin $\mathrm{Xi}$ \\ Ying Ji \\ Qiao Ren \\ Huan Ning \\ Shaoyan Wang
}

The Department of

Dermatovenereology, The Second

Hospital of Shanxi Medical University,

Taiyuan, 03000I, Shanxi, People's

Republic of China
Correspondence: Wenli Feng; Jing Yang The Department of Dermatovenereology, The Second Hospital of Shanxi Medical University, No. 382, Wuyi Road, Taiyuan, Shanxi, 03000I, People's Republic of China

Tel +86-035I-3365410

Email wenlifeng2010@।63.com;

yangjing7962@I26.com
Purpose: This study aimed to investigate the effects of aspirin (acetyl salicylic acid [ASA]) combined with fluconazole (FCA), itraconazole (ITR), or voriconazole (VRC) on Candida albicans under planktonic and biofilm conditions.

Methods: A total of 39 clinical $C$. albicans strains were used to perform the in vitro drug sensitivity assay under different conditions using the M27-A4 broth microdilution method. The minimal inhibitory concentrations (MICs) and fractional inhibitory concentration index (FICI) values were calculated. C. albicans ZY23 was chosen for the further analyses.

Results: Under planktonic conditions, the half maximal $\mathrm{MIC}\left(\mathrm{MIC}_{50}\right)$ values of FCA, ITR, and VRC were $64-0.5 \mu \mathrm{g} / \mathrm{mL}, 32-0.0625 \mu \mathrm{g} / \mathrm{mL}$, and $16-0.125 \mu \mathrm{g} / \mathrm{mL}$, respectively, when applied, whereas in combination with ASA, the values decreased to $32-0.25 \mu \mathrm{g} / \mathrm{mL}$, $8-0.0313 \mu \mathrm{g} / \mathrm{mL}$, and $8-0.0313 \mu \mathrm{g} / \mathrm{mL}$, respectively. Under biofilm conditions, FCA, ITR, or VRC alone showed $\mathrm{MIC}_{50}$ values of $128-8 \mu \mathrm{g} / \mathrm{mL}, 32-4 \mu \mathrm{g} / \mathrm{mL}$, and $32-0.5 \mu \mathrm{g} / \mathrm{mL}$, whereas in combination with ASA the values were decreased to $32-0.5 \mu \mathrm{g} / \mathrm{mL}, 16-0.5 \mu \mathrm{g} /$ $\mathrm{mL}$, and $8-0.0625 \mu \mathrm{g} / \mathrm{mL}$, respectively. Analysis of the FICI showed that the sensitization rate of ASA to FCA, ITR, and FCA under planktonic conditions was $43.59 \%$, whereas the sensitization rates of ASP to FCA, ITR, and FCA under biofilm conditions were $46.15 \%$, $46.15 \%$, and $48.72 \%$, respectively. Additionally, the time-growth and time-kill curves of C. albicans ZY23 further verified the synergistic effects of ASA on azole drugs.

Conclusion: ASA may act as an enhancer of the inhibitory effects of azole drugs on the growth of clinical C. albicans under planktonic and biofilm conditions.

Keywords: acetylsalicylic acid, synergistic effects, invasive fungus, virulence

\section{Introduction}

Invasive fungi have become an important cause of serious and fatal infections over the past few decades, and the associated infections cause dangerous diseases with rapid clinical progression, poor prognosis, and high fatality rates. ${ }^{1}$ Candidiasis, mainly caused by Candida albicans, is a serious invasive fungal infection that is ranked as the fourth most prevalent nosocomial bloodstream infections in hospitals, with a mortality rate of up to $50 \%{ }^{2-5}$ The severity of $C$. albicans infections is closely related to virulence factors, such as phenotypic transformation, invasive enzymes, adhesion factors, and host and environmental factors. ${ }^{6}$ Currently, only a few types of antifungal agents including azoles, echinocandins, polyenes, and allylamines are available for the management of $C$. albicans infections. ${ }^{7}$ Fluconazole (FCA), itraconazole (ITR), and voriconazole (VRC) are azole drugs commonly used for the treatment of infections caused by $C$. albicans because of their high bioavailability. ${ }^{8}$ However, the 
extensive and frequent use of azole drugs has gradually increased the number of drug-resistant strains of C. albicans, which has become a great challenge in the treatment of fungal infections. In addition, C. albicans easily form biofilms on medical devices, which can reduce its susceptibility to drugs and is thought to be physiologically related to the acquisition of drug resistance against antifungal agents. ${ }^{9,10}$ Therefore, drug resistance has become an important challenge in the treatment of $C$. albicans infections. There is an urgent need to develop improved and novel antifungal therapies to reduce drug resistance of $C$. albicans in treating candidiasis.

Candidiasis can cause host cells to release proinflammatory cytokines and large amounts of arachidonic acid (AA). Subsequently, AA can be converted to eicosanoids by lipoxygenases and cyclooxygenases (COXs), and prostaglandins (PGs) may play an important role in fungal colonization. $^{11}$ Non-steroidal anti-inflammatory drugs (NSAIDs) are inhibitors of COX-1 and COX-2 isoenzymes. The NSAID aspirin (acetylsalicylic acid [ASA]) blocks the production of PG E2 (PGE2) by inhibiting the activity of COXs, and PGE2 promotes the formation of fungal hyphae. ${ }^{12}$ Additionally, ASA has been reported to increase the sensitivity of FCA-resistant strains of C. albicans, reduce the adhesion of C. albicans to abiotic surfaces, and inhibit the growth of $C$. albicans in the planktonic state. ${ }^{13}$ Rusu et $\mathrm{l}^{14}$ reported that ASA effectively reduced the formation of germ tubes by C. albicans and inhibited fungal viability. Previous studies have shown that in combination with amphotericin B, ASA influences the formation of biofilms of $C$. albicans by upregulating its glucoamylase 1 (GAM1) homolog GCA1 and downregulating cell division cycle mutant 35 (CDC35), CSR1, enhanced filamentous growth protein 1 (EFGl), and hyphal wall protein 1 (HWP1), thus, improving the efficacy of amphotericin B. ${ }^{15,16}$ However, the combined effects of ASA and azole drugs on C. albicans remain unclear.

In this study, biofilms of a clinical C. albicans strain were formed, and in vitro drug sensitivity tests were conducted using the M27-A4 broth microdilution method under planktonic and biofilm conditions. Based on the results of drug sensitivity, the enhancement of the growth inhibiting effects of azole drugs by ASA was explored. These findings provide potential novel approaches for the clinical treatment of diseases caused by C. albicans infection.

\section{Materials and Methods}

\section{Experimental Strains}

A total of 39 clinical strains of $C$. albicans were provided by the Fungal Laboratory, Department of Dermatology and The Second Hospital of Shanxi Medical University (Shanxi, China), and their origins are shown in Table 1. In addition, a standard strain of C. albicans (ATCC 11006) and quality control strains (Candida krusei ATCC 6258 and Candida parapsilosis ATCC 22019) were purchased from the Fungus and Mycosis Research Center, Department of Medicine, Peking University (Beijing, China).

\section{Preparation of Drug Stock Solutions}

ASA, FCA, ITR, and VRC were purchased from Beijing Runzekang Biological Technology Co., Ltd. (Beijing, China). The stock solution of ASA $(32 \mathrm{mg} / \mathrm{mL})$ was prepared by dissolving $160 \mathrm{mg}$ ASA powder in $5 \mathrm{~mL}$ dimethyl sulfoxide (DMSO, Sangon Biotech (Shanghai) Co., Ltd., Shanghai, China). Furthermore, $6.4 \mathrm{mg}$ of FCA powder was dissolved in $5 \mathrm{~mL}$ sterilized double distilled water, and a stock solution of a concentration of $1280 \mu \mathrm{g} / \mathrm{mL}$ was prepared. Additionally, $3.2 \mathrm{mg}$ ITR or VRC was dissolved in $1 \mathrm{~mL}$ DMSO, and a stock solution of each agent at a concentration of $3200 \mu \mathrm{g} / \mathrm{mL}$ was prepared. All stock solutions were stored at $-20^{\circ} \mathrm{C}$.

\section{Preparation of Fungal Suspension Under Planktonic and Biofilm Conditions}

C. albicans was inoculated into yeast extract peptone dextrose (YPD) liquid medium (Saipuruisi Beijing Technology Co., Ltd., Beijing, China), cultured overnight, and then $1 \mathrm{~mL}$ of the fungal suspension was centrifuged at high speed for $2 \mathrm{~min}$ and then washed twice with saline. Then, C. albicans was resuspended in Roswell Park Memorial Institute (RPMI) 1640 medium (Saipuruisi Beijing Technology Co., Ltd.) and diluted to $1 \times 10^{3} \mathrm{CFU} /$ $\mathrm{mL}$. A fungal suspension was prepared to measure drug sensitivity under planktonic conditions.

Fungal suspensions were prepared under biofilm conditions as previously described. ${ }^{17,18}$ The experimental strains were inoculated into a YPD agar medium (Saipuruisi Beijing Technology Co., Ltd.), cultured at $37^{\circ}$ $\mathrm{C}$ for $72 \mathrm{~h}$, and then a fresh single colony was selected for inoculation into YPD liquid medium, followed by culturing at $30^{\circ} \mathrm{C}$ for $24 \mathrm{~h}$ with agitation at $200 \mathrm{rpm}$. The fungal suspension $(1 \mathrm{~mL})$ was collected into a new $1.5 \mathrm{~mL}$ tube 
Table I The Clinical Features of the Patients Where the Strains Were Isolated

\begin{tabular}{|c|c|c|c|c|}
\hline Strain (ZY) & Gender & Age & Source & Symptom \\
\hline 1 & Female & 53 & Urine & Dysuria, urgency, and frequency \\
\hline 4 & Female & 61 & Sputum & Fever, cough and sputum \\
\hline 7 & Male & 55 & Faeces & Diarrhea \\
\hline 9 & Male & 56 & Sputum & Fever, cough and sputum \\
\hline II & Female & 65 & Sputum & Fever, cough and sputum \\
\hline 12 & Female & 65 & Sputum & Fever, cough and sputum \\
\hline 15 & Female & 76 & Sputum & Fever, cough and sputum \\
\hline 18 & Male & 24 & Sputum & Fever, cough and sputum \\
\hline 20 & Female & 86 & Sputum & Fever, cough and sputum \\
\hline 21 & Female & 56 & Sputum & Fever, cough and sputum \\
\hline 22 & Female & 56 & Sputum & Fever, cough and sputum \\
\hline 23 & Female & 40 & Urine & Urgency, and frequency \\
\hline 24 & Male & 78 & Urine & Dysuria, urgency, and frequency \\
\hline 26 & Female & 62 & Urine & Dysuria, urgency, and frequency \\
\hline 27 & Female & 53 & Sputum & Fever, cough and sputum \\
\hline 28 & Female & 26 & Sputum & Fever, cough and sputum \\
\hline 30 & Male & 72 & Sputum & Fever, cough and sputum \\
\hline 33 & Female & 30 & Sputum & Fever, cough and sputum \\
\hline 35 & Male & 48 & Sputum & Fever, cough and sputum \\
\hline 36 & Male & 88 & Sputum & Fever, cough and sputum \\
\hline 38 & Female & 45 & Sputum & Fever, cough and sputum \\
\hline 39 & Male & 19 & Sputum & Fever, cough and sputum \\
\hline 40 & Female & 71 & Faeces & Diarrhea \\
\hline $4 I$ & Female & 45 & Vaginal secretion & Increased vaginal discharge accompanied by pruritus \\
\hline 42 & Female & 19 & Vaginal secretion & Increased vaginal discharge accompanied by pruritus \\
\hline 43 & Female & 38 & Vaginal secretion & Increased vaginal discharge accompanied by pruritus \\
\hline 44 & Female & 50 & Vaginal secretion & Increased vaginal discharge accompanied by pruritus \\
\hline 45 & Female & 22 & Vaginal secretion & Increased vaginal discharge accompanied by pruritus \\
\hline 46 & Female & 55 & Vaginal secretion & Increased vaginal discharge accompanied by pruritus \\
\hline 47 & Female & 30 & Vaginal secretion & Increased vaginal discharge accompanied by pruritus \\
\hline 48 & Female & 29 & Vaginal secretion & Increased vaginal discharge accompanied by pruritus \\
\hline 50 & Female & 48 & Vaginal secretion & Increased vaginal discharge accompanied by pruritus \\
\hline 51 & Female & 60 & Vaginal secretion & Increased vaginal discharge accompanied by pruritus \\
\hline
\end{tabular}


Table I (Continued).

\begin{tabular}{|l|l|l|l|l|}
\hline Strain (ZY) & Gender & Age & Source & Symptom \\
\hline 52 & Female & 27 & Vaginal secretion & Increased vaginal discharge accompanied by pruritus \\
\hline 53 & Female & 55 & Vaginal secretion & Increased vaginal discharge accompanied by pruritus \\
\hline 55 & Male & 67 & Urine & Dysuria, urgency, and frequency \\
\hline 56 & Male & 24 & Urine & Dysuria, urgency, and frequency \\
\hline 63 & Female & 72 & Urine & Dysuria, urgency, and frequency \\
\hline 64 & Male & 58 & Urine & Dysuria, urgency, and frequency \\
\hline
\end{tabular}

and centrifuged at $5000 \mathrm{rpm}$ for $2 \mathrm{~min}$. The sediment was washed with saline three times, resuspended in RPMI 1640 medium, and then $100 \mu \mathrm{L}$ of the fungal suspension was added to each well of a 96-well plate, whereas $100 \mu \mathrm{L}$ RPMI1640 medium was used as a negative control. After culturing at $37^{\circ} \mathrm{C}$ for $1 \mathrm{~h}$, sterile phosphate-buffered saline (PBS) was added to remove the free cells, and then $100 \mu \mathrm{L}$ of fresh RPMI1640 medium was added. After culturing at $37^{\circ} \mathrm{C}$ for $24 \mathrm{~h}$, the fungi were washed with PBS three times, the medium was removed, and then the fungi were incubated at $37^{\circ} \mathrm{C}$ for another $24 \mathrm{~h}$ to form mature biofilms.

\section{Drug Sensitivity Assays Under Different Conditions}

A two-fold dilution method was used to prepare the ASA, FCA, ITR, and VRC solutions in RPMI medium. For the experiments under planktonic conditions, the concentrations of ASA, FCA, ITR, and VRC used were from $16 \mathrm{mg} / \mathrm{mL}$ to $0.25 \mathrm{mg} / \mathrm{mL}, 64 \mu \mathrm{g} / \mathrm{mL}$ to $0.125 \mu \mathrm{g} / \mathrm{mL}, 16 \mu \mathrm{g} / \mathrm{mL}$ to 0.0313 $\mu \mathrm{g} / \mathrm{mL}$, and $16 \mu \mathrm{g} / \mathrm{mL}$ to $0.0313 \mu \mathrm{g} / \mathrm{mL}$, respectively. In addition, under biofilm conditions, the concentrations of ASA, FCA, ITR, and VRC used ranged from $32 \mathrm{mg} / \mathrm{mL}$ to $0.5 \mathrm{mg} / \mathrm{mL}, 128 \mu \mathrm{g} / \mathrm{mL}$ to $0.25 \mu \mathrm{g} / \mathrm{mL}, 32 \mu \mathrm{g} / \mathrm{mL}$ to 0.0625 $\mu \mathrm{g} / \mathrm{mL}$, and $32 \mu \mathrm{g} / \mathrm{mL}$ to $0.0625 \mu \mathrm{g} / \mathrm{mL}$, respectively.

Drug sensitivity was analyzed in vitro using the Clinical Laboratory and Standards Institute (CLSI) standard M27-A4 broth microdilution method. ${ }^{19}$

Under planktonic conditions, each concentration of FCA, ITR, or VRC $(100 \mu \mathrm{L})$ was added to the specified wells of a 96-well plate, followed by different concentrations of ASA $(100 \mu \mathrm{L})$ and then $100 \mu \mathrm{L}$ of the fungal suspension was added to each well (except for the negative control). RPMI medium was used as the negative control, and the fungal suspension without any treatment was used as the positive control. Under biofilm conditions, the C. albicans biofilm was successfully established on a 96well plate, and then the drug treatment was similar to that under planktonic conditions. After culturing at $37^{\circ} \mathrm{C}$ for 48 $\mathrm{h}$, the minimal inhibitory concentrations (MICs) were calculated based on the growth of $C$. albicans on a 96-well plate as previously described. ${ }^{20,21}$

\section{Interpretation of Fractional Inhibitory Concentration Index ( $\mathrm{FICl})$}

The fractional inhibitory concentration index (FICI) was used to determine the interaction of the two drugs in combination, and the results were interpreted according to the methods of Tamura et $\mathrm{al}^{22}$ and Odds et al. ${ }^{23}$ The following formula was used for the calculation: $\mathrm{FICI}=$ $\left(\mathrm{MIC}_{\mathrm{A}}\right.$ in combination/ $\mathrm{MIC}_{\mathrm{A}}$ alone $)+\left(\mathrm{MIC}_{\mathrm{B}}\right.$ in combination/ $\mathrm{MIC}_{\mathrm{B}}$ alone). The effects of the antifungal drug combinations were classified according to the following criteria: (1) FICI $\leq 0.5$, synergistic effects; (2) $0.5<$ FICI $\leq 1$, additive effects; (3) $1<$ FICI $<4$, no interactions; (4) FICI $\geq 4$.0, antagonistic effects.

\section{Time-Growth and Time-Kill Curve Assays}

C. albicans ZY23 was chosen to perform the time-growth and time-kill assays to construct the respective curves. The overnight cultured ZY23 suspension was washed with PBS three times and resuspended in a YPD liquid medium to a final concentration of $1 \times 10^{4} \mathrm{CFU} / \mathrm{mL}$. The concentrations of ASA, FCA, ITR, and VRC were selected based on the results of the drug sensitivity experiment. The control group consisted of 
$0.5 \mathrm{~mL}$ fungal suspension and 4.5 mL RPMI medium. The single-drug group was $0.5 \mathrm{~mL}$ fungi suspension, $0.5 \mathrm{~mL}$ FCA $(8 \mu \mathrm{g} / \mathrm{mL}) / \mathrm{ITR}(4 \mu \mathrm{g} / \mathrm{mL}) / \mathrm{VRC}(4 \mu \mathrm{g} / \mathrm{mL})$, and $4 \mathrm{~mL}$ RPMI 1640 medium. The combination groups consisted of $0.5 \mathrm{~mL}$ fungi suspension, $0.5 \mathrm{~mL}$ FCA $(8 \mu \mathrm{g} / \mathrm{mL}) / \mathrm{ITR}(4 \mu \mathrm{g} / \mathrm{mL}) /$ VRC ( $4 \mu \mathrm{g} / \mathrm{mL}), 0.5 \mathrm{~mL}$ different concentrations of ASA (1, 2, 4, and $8 \mathrm{mg} / \mathrm{mL}$ ), and $3.5 \mathrm{~mL}$ RPMI 1640 medium. After incubation at $37^{\circ} \mathrm{C}$ with oscillation at $200 \mathrm{rpm}$ for $0,12,36$, and $48 \mathrm{~h}$, the absorbance at $630 \mathrm{~nm}$ was measured using a microplate reader, and the curve was plotted to record the growth of $C$. albicans ZY22 at each time point. ${ }^{24}$

For the time-kill curve experiments, ${ }^{25}$ C. albicans ZY23 was cultured in YPD liquid medium for $16 \mathrm{~h}$, and then the fungal suspension $(100 \mu \mathrm{L})$ was transferred to fresh YPD liquid medium $(10 \mathrm{~mL})$. After culturing for another $4 \mathrm{~h}$, the fungi were washed with PBS three times and resuspended in RPMI medium to a final concentration of $1 \times 10^{3} \mathrm{CFU} / \mathrm{mL}$. The control group consisted of a $0.5 \mathrm{~mL}$ fungal suspension, a $0.5 \mathrm{~mL}$ DMSO, and a $4 \mathrm{~mL}$ RPMI medium. The singledrug groups contained $0.5 \mathrm{~mL}$ fungal suspension with $0.5 \mathrm{~mL}$ FCA $(8 \mu \mathrm{g} / \mathrm{mL})$, ITR $(4 \mu \mathrm{g} / \mathrm{mL})$, or VRC $(4 \mu \mathrm{g} /$ $\mathrm{mL}$ ) and $4 \mathrm{~mL}$ RPMI medium. The combination groups included $0.5 \mathrm{~mL}$ fungi suspension; $0.5 \mathrm{~mL} \mathrm{FCA}$, ITR, or VRC; $0.5 \mathrm{~mL}$ ASA; and $3.5 \mathrm{~mL}$ RPMI medium. The mixture was incubated at $30^{\circ} \mathrm{C}$ with oscillation at $220 \mathrm{rpm}$. After culturing for $0,12,24,36$, and $48 \mathrm{~h}$, the fungal suspension was diluted using a 10-fold dilution method, and then coated on Sabouraud dextrose agar (SDA) medium (Saipuruisi Beijing Technology Co., Ltd.). After culturing at $30^{\circ} \mathrm{C}$ for $48 \mathrm{~h}$, the fungal colonies were counted and the $\log _{10} \mathrm{CFU} /$ $\mathrm{mL}$ values were used to draw the curves for the analysis.

\section{Statistical Analysis}

Data are presented as means \pm standard deviation (SD) and the statistical package for the social sciences (SPSS) software (version 17.0; SPSS, Inc., Chicago, IL, USA) was used for statistical analyses. Differences between the two groups were analyzed using the Student's $t$-test and a oneway analysis of variance (ANOVA) was used to compare more than two groups, while differences were considered statistically significant at $\mathrm{p}<0.05$.

\section{Results}

\section{Drug Sensitivity Under Free and Biofilm Conditions}

The CLSI standard M27-A4 broth microdilution method was used to determine the $\mathrm{MIC}_{50}$ of $\mathrm{ASA}, \mathrm{FCA}$, ITR, and
VRC against classical C. albicans strains under planktonic and biofilm conditions. The $\mathrm{MIC}_{50}$ values under different conditions are shown in Tables 2, 3 and $\underline{\mathrm{S} 1}-\underline{\mathrm{S}} 4$. The results showed that the $\mathrm{MIC}_{50}$ of FCA alone was $64-0.5 \mu \mathrm{g} / \mathrm{mL}$ and $128-8 \mu \mathrm{g} / \mathrm{mL}$ under planktonic and biofilm conditions, respectively, whereas in combination with ASA the values were decreased to $32-0.25 \mu \mathrm{g} / \mathrm{mL}$, and $32-0.5 \mu \mathrm{g} / \mathrm{mL}$, respectively (Tables 2 and 3 ).

Under planktonic conditions, the $\mathrm{MIC}_{50}$ values of ITR and VRC alone were $32-0.0625 \mu \mathrm{g} / \mathrm{mL}$ and $16-0.125 \mu \mathrm{g} /$ $\mathrm{mL}$, respectively, whereas the values decreased to 8-0.0313 $\mu \mathrm{g} / \mathrm{mL}$ and $8-0.0313 \mu \mathrm{g} / \mathrm{mL}$, respectively, in combination with ASA (Tables S1 and S3). In addition, under biofilm conditions, the $\mathrm{MIC}_{50}$ values of ITR and VRC alone were $32-4 \mu \mathrm{g} / \mathrm{mL}$ and $32-0.5 \mu \mathrm{g} / \mathrm{mL}$, respectively, whereas cotreatment with ASA decreased the values to $16-0.5 \mu \mathrm{g} / \mathrm{mL}$ and $8-0.0625 \mu \mathrm{g} / \mathrm{mL}$, respectively (Tables S2 and S3). These results indicate that compared to treatment with FCA, ITR, or VRC alone, co-treatment with ASA decreased the $\mathrm{MIC}_{50}$ values of the agents against clinical $C$. albicans under planktonic and biofilm conditions.

\section{Interaction of FCA, ITR, or VRC with ASA Against C. albicans}

FICI values were calculated to further analyze the effects of the interaction between ASA and FCA, ITR, or VRC on the sensitivity of $C$. albicans. Synergistic interactions between FCA and ASA under planktonic and biofilm conditions were observed in 17 and 18 strains, respectively, with FICI $\leq 0.5$, additive interactions were observed in 17 and 17 strains, respectively, with $0.5<$ FICI $\leq 1$; and 5 and 4 strains, respectively, showed no interaction (Table 4). For ITR and ASA, synergistic interactions were found in 17 and 18 strains under planktonic and biofilm conditions, respectively, whereas additive interactions were observed in 18 and 17 strains, respectively (Table 4).

Additionally, under planktonic conditions, synergistic and additive interactions were observed between ASA and VRC in 17 strains each and no interaction was observed in 5 strains. In contrast, under biofilm conditions, synergistic and additive interactions were observed in 19 and 16 strains, respectively, whereas no interaction was observed in 4 strains (Table 4). In summary, the rate at which ASA enhanced the potency of FCA, ITR, and FCA under planktonic conditions was $43.59 \%$; whereas corresponding 


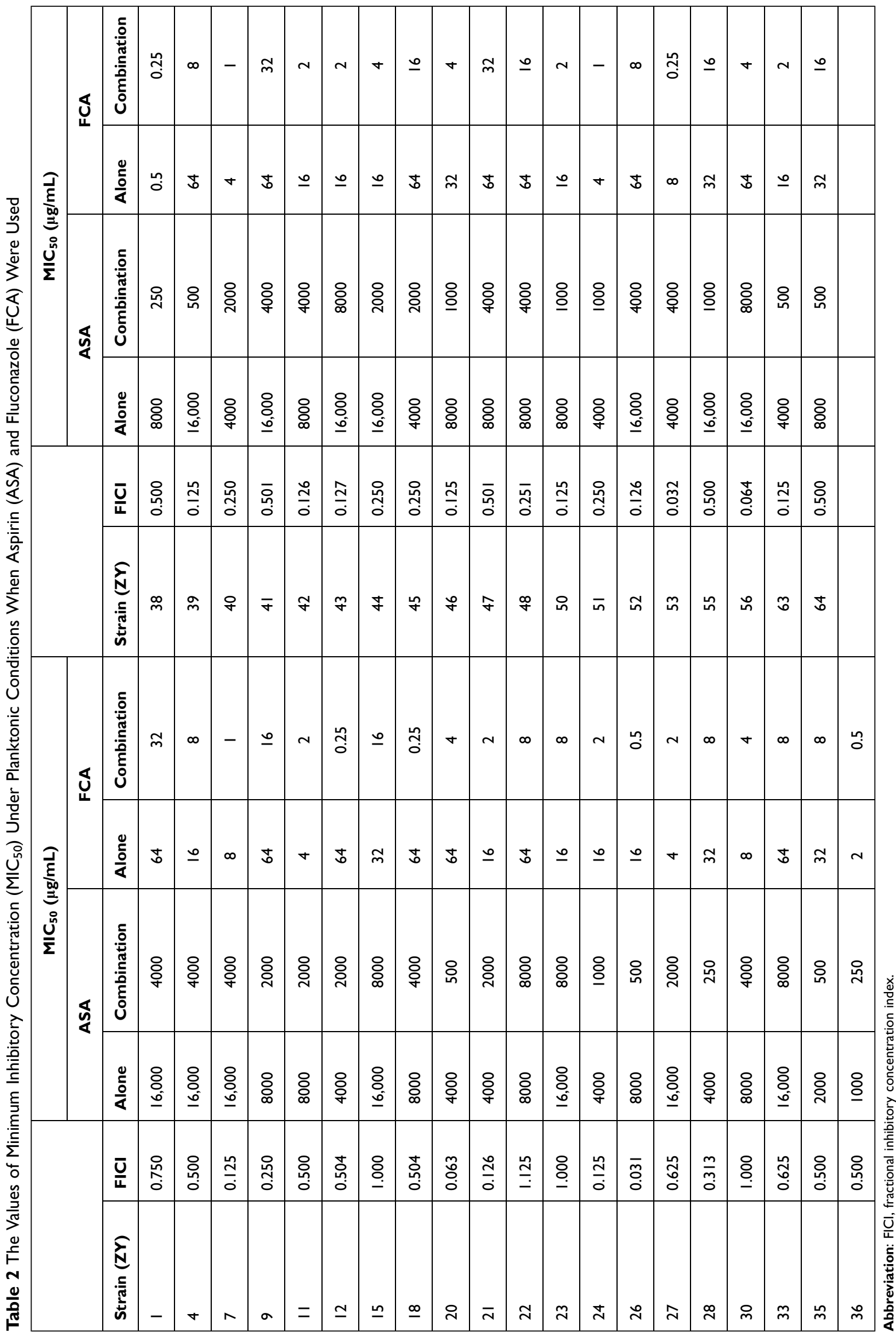




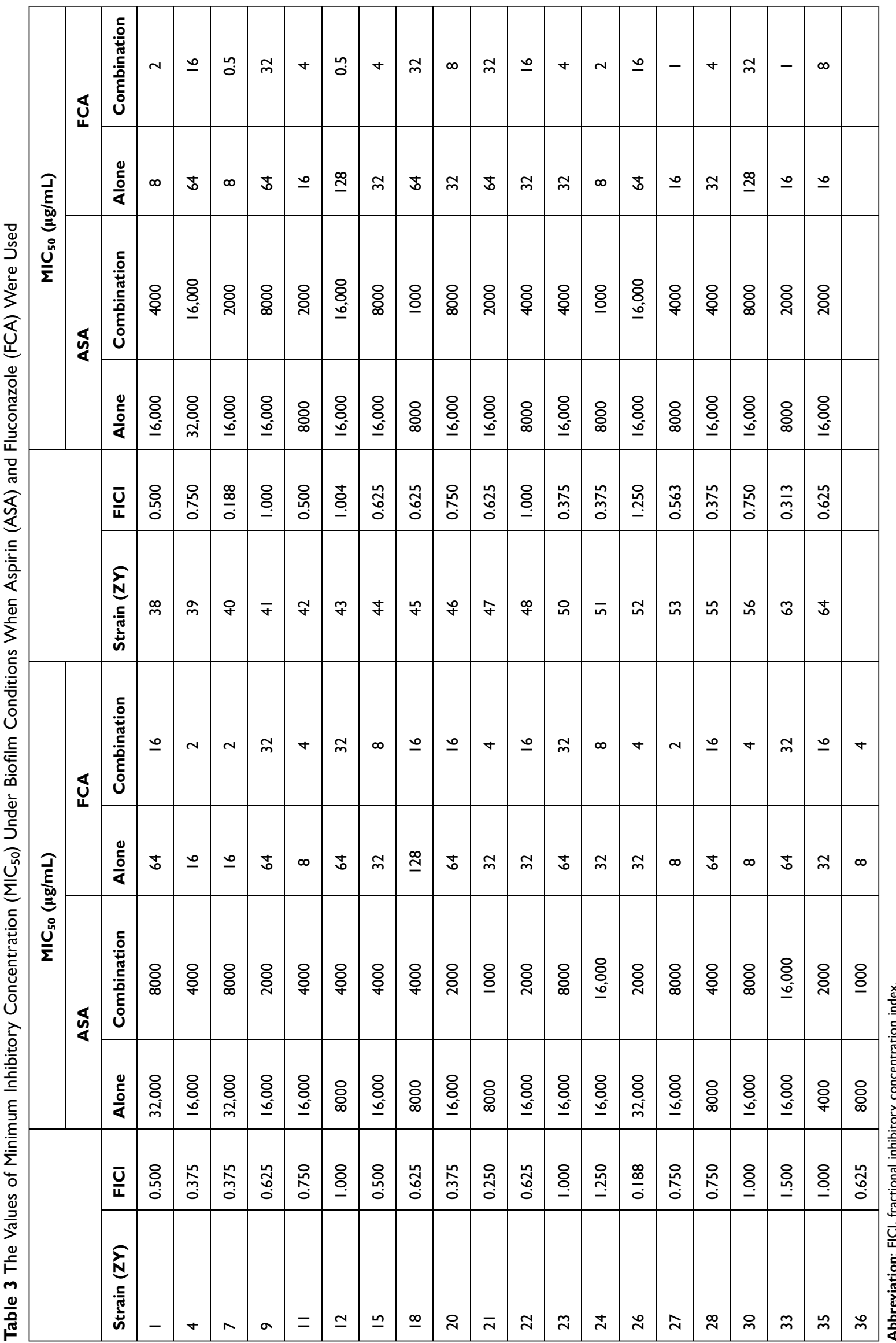


Table 4 The Interactions Between Aspirin (ASA) and Fluconazole (FCA), Itraconazole (ITR) or Voriconazole (VRC) Under Different Conditions

\begin{tabular}{|l|c|c|c|c|c|c|}
\hline \multirow{2}{*}{} & \multicolumn{2}{|c|}{ ASA Combined with FCA } & \multicolumn{2}{c|}{ ASA Combined with ITR } & \multicolumn{2}{c|}{ ASA Combined with VRC } \\
\cline { 2 - 7 } & $\begin{array}{c}\text { Planktonic } \\
\text { Conditions }\end{array}$ & $\begin{array}{c}\text { Biofilm } \\
\text { Conditions }\end{array}$ & $\begin{array}{c}\text { Planktonic } \\
\text { Conditions }\end{array}$ & $\begin{array}{c}\text { Biofilm } \\
\text { Conditions }\end{array}$ & $\begin{array}{c}\text { Planktonic } \\
\text { Conditions }\end{array}$ & $\begin{array}{c}\text { Biofilm } \\
\text { Conditions }\end{array}$ \\
\hline Synergistic $(\mathrm{FICl} \leq 0.5)$ & 17 & 18 & 17 & 18 & 17 & 17 \\
Additive $(0.5<\mathrm{FICl} \leq 1)$ & 17 & 17 & 18 & 17 & 17 & 16 \\
No interaction $(\mathrm{I}<\mathrm{FICl}<4)$ & 5 & 4 & 4 & 4 & 0 & 0 \\
Antagonistic (FICl $\geq 4)$ & 0 & 0 & 0 & 0 & 4 \\
Sensitization rate & $43.59 \%$ & $46.15 \%$ & $43.59 \%$ & $46.15 \% \%$ & $43.59 \%$ & $48.72 \%$ \\
\hline
\end{tabular}

Abbreviation: $\mathrm{FICl}$, fractional inhibitory concentration index.

enhancement rates for the agents under biofilm conditions were $46.15 \%, 46.15 \%$, and $48.72 \%$, respectively.

\section{Time-Growth Curves}

C. albicans ZY23 was treated with FCA, ITR, or VRC alone or in combination with different concentrations of ASA to construct time-growth curves. As shown in Figure $1,8 \mu \mathrm{g} / \mathrm{mL}$ FCA, $4 \mu \mathrm{g} / \mathrm{mL}$ ITR, or $4 \mu \mathrm{g} / \mathrm{mL}$ VRC inhibited the growth of $C$. albicans ZY23. Compared with the FCA alone group, FCA combined with ASA further inhibited the growth of ZY23, and ASA at a concentration of $8 \mathrm{mg} / \mathrm{mL}$ showed better synergistic inhibitory effects than it did at $4 \mathrm{mg} / \mathrm{mL}$ (Figure $1 \mathrm{~A}$ ).

There was no significant difference in ZY23 growth among the ITR alone, ITR combined with $1 \mathrm{mg} / \mathrm{mL}$ ASA, and ITR combined with $2 \mathrm{mg} / \mathrm{mL}$ ASA groups. ITR
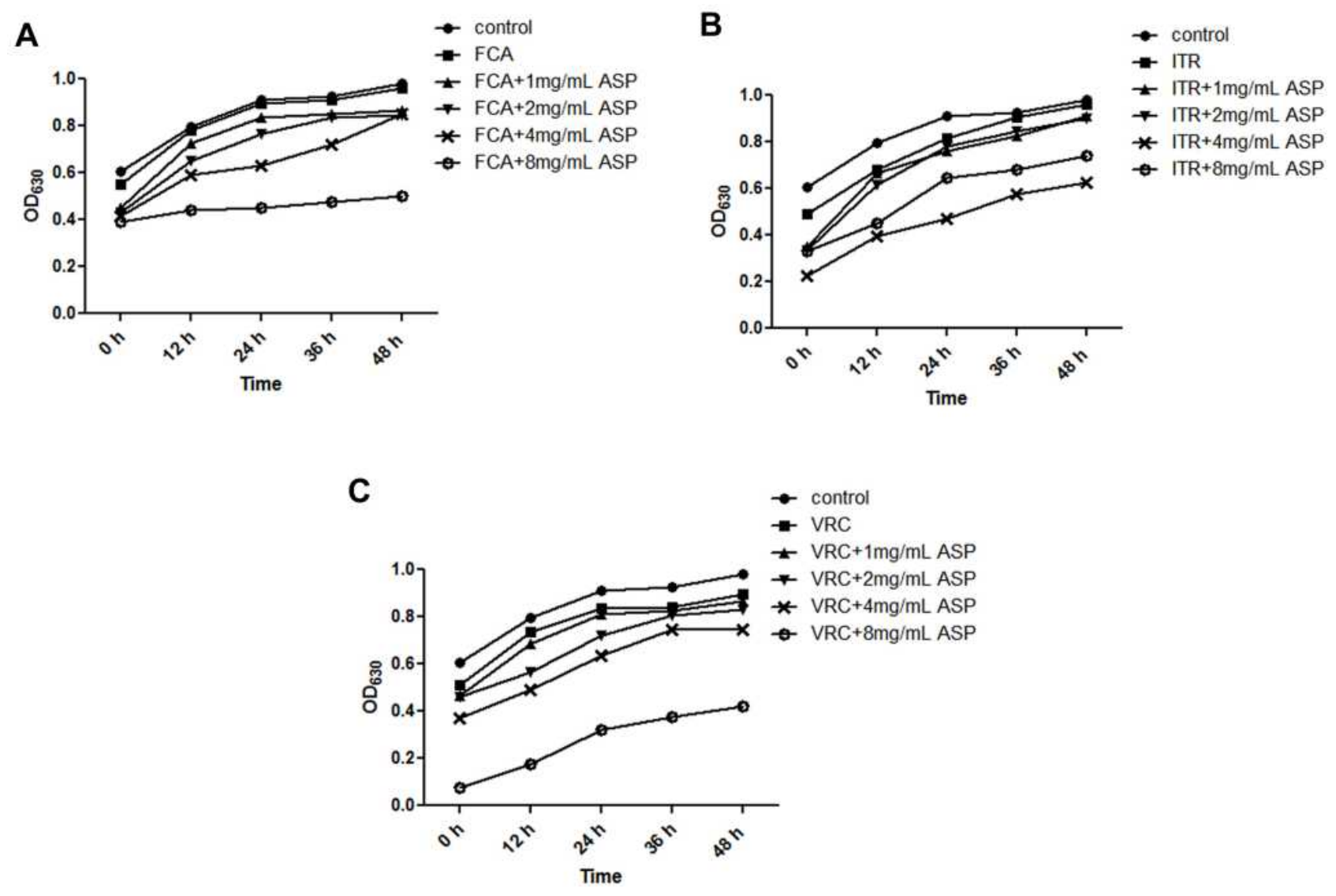

Figure I Time-growth curves of Candida albicans ZY23. Time-growth curves of ZY23 treated with (A) fluconazole (FCA) (B) itraconazole (ITR) or (C) voriconazole (VRC) alone or in combination with different concentrations of aspirin (ASA). 
combined with $4 \mathrm{mg} / \mathrm{mL}$ or $8 \mathrm{mg} / \mathrm{mL}$ ASA suppressed the growth of ZY23 more than it had done alone, and showed better effects in combination with $4 \mathrm{mg} / \mathrm{mL}$ ASA (Figure 1B). Furthermore, treatment with VRC alone or in combination showed a similar trend to that with FCA or ITR. VRC in combination with $8 \mathrm{mg} / \mathrm{mL}$ ASA showed obviously better inhibitory effects on $C$. albicans than it had done alone (Figure 1C). Based on these results, $8 \mu \mathrm{g} /$ $\mathrm{mL}$ FCA combined with $8 \mathrm{mg} / \mathrm{mL}$ ASA, $4 \mu \mathrm{g} / \mathrm{mL}$ ITR combined with $4 \mathrm{mg} / \mathrm{mL}$ ASA, and $4 \mu \mathrm{g} / \mathrm{mL}$ VRC combined with $8 \mathrm{mg} / \mathrm{mL} \mathrm{VPL}$ were chosen for the subsequent time-kill curve experiments.

\section{Time-Kill Curves}

After drug treatment, the total number of colonies at each time point was calculated to assess the synergistic inhibitory effect of the drugs on the $C$. albicans strain. After a $2 \mathrm{~h}$ culture, the growth of ZY23 was significantly inhibited by FCA alone and in combination with ASA, whereas the inhibitory effect of FCA alone on C. albicans was not obvious after a 24, 36, and 48 $\mathrm{h}$ culture compared to the control treatment. Compared with the FCA alone group, the number of $C$. albicans colonies in the FCA plus ASA group was lower, suggesting that the combination could have better inhibitory effects on the growth of $C$. albicans than FCA alone (Figure 2A). The inhibitory effect of ITR or VRC alone or in combination was similar to that of FCA alone or in combination (Figure $2 \mathrm{~B}$ and $\mathrm{C}$ ). These results indicated that azole drugs may have more significant inhibitory effects on $C$. albicans in combination with ASA than they do alone.

\section{Discussion}

Recently, drug combinations have become an effective strategy to overcome the increasing resistance of C. albicans and other pathogenic diseases causing organisms. ASA is mainly used for its antipyretic, analgesic, and anti-inflammatory activities. Previous studies have shown that ASA increased the sensitivity of FCA-resistant strains and inhibited the growth of $C$. albicans under planktonic conditions. $^{26,27}$ In our experiment under planktonic conditions, the $\mathrm{MIC}_{50}$ values of FCA, ITR, or VRC applied alone were $64-0.5 \mu \mathrm{g} / \mathrm{mL}, 32-0.0625 \mu \mathrm{g} / \mathrm{mL}$, and 16-0.125 $\mu \mathrm{g} / \mathrm{mL}$, respectively, whereas cotreatment with ASA decreased the values to $32-0.25 \mu \mathrm{g} / \mathrm{mL}, 8-0.0313$ $\mu \mathrm{g} / \mathrm{mL}$ and $8-0.0313 \mu \mathrm{g} / \mathrm{mL}$, respectively. Additionally, the rate of enhancement of the inhibitory activities of FCA, ITR, and FCA by ASA under planktonic conditions
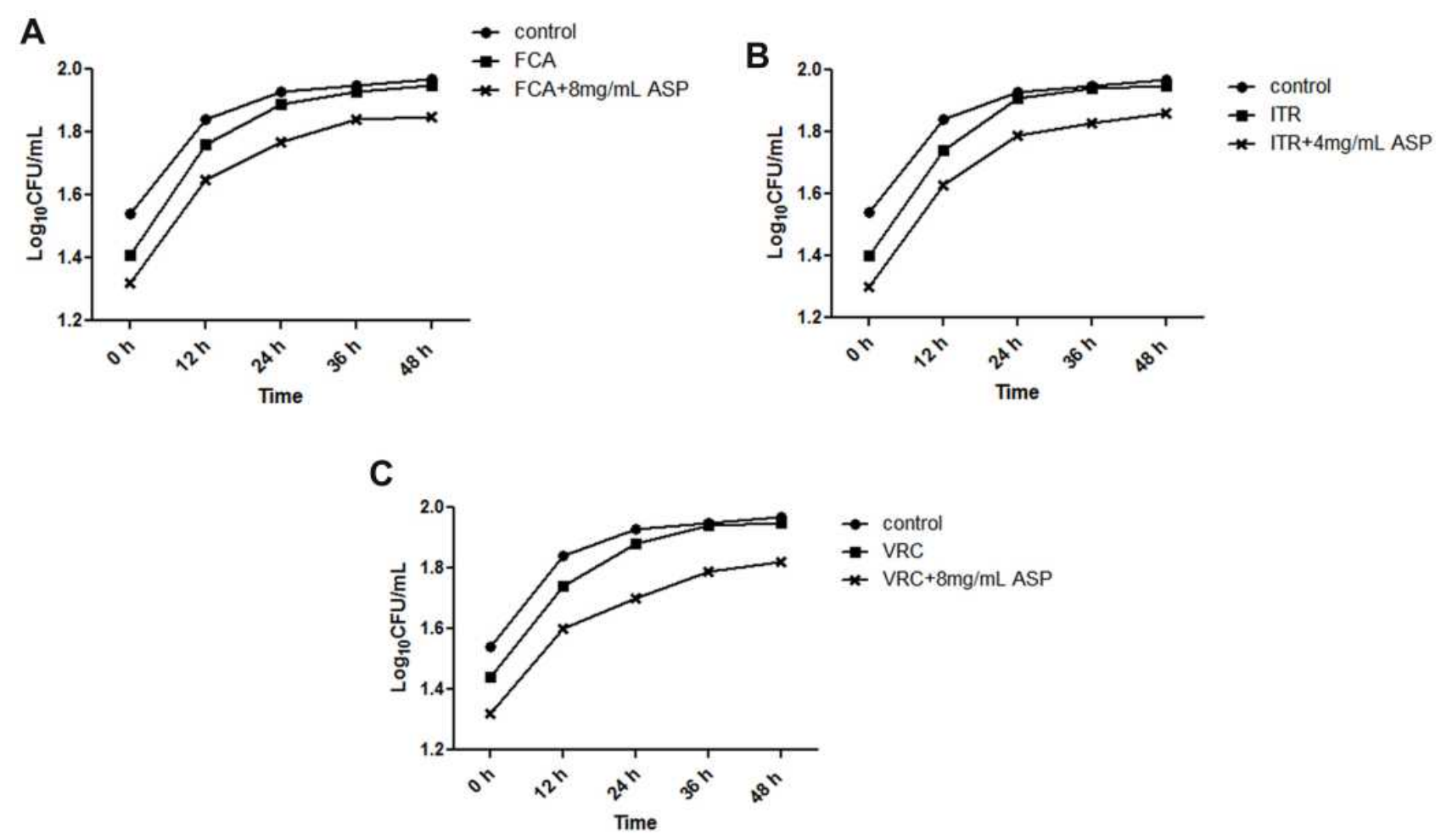

Figure 2 Time-kill curves of Candida albicans ZY23 treated with (A) fluconazole (FCA) (B) itraconazole (ITR), and (C) voriconazole (VRC) alone or combination. 
was $43.59 \%$. In addition, the results of the time-growth and time-kill curve assays also showed that compared to treatment with each azole drug alone, cotreatment with ASA further enhanced the growth inhibition of C. albicans ZY23. A previous study by Pina-Vaz et $\mathrm{al}^{28}$ showed that cotreatment with ibuprofen and FCA showed synergic activity against 8 of the 12 Candida strains tested, including four of the five FCA-resistant strains, indicating that ibuprofen increased their sensitivity. Another study demonstrated that the cotreatment with FCA and ibuprofen, propylparaben, or sodium salicylate resulted in a synergistic activity with an FICI $<0.5$ against C. albicans NCYC610. ${ }^{29}$ Feng et $\mathrm{al}^{24}$ also reported that ASA and verapamil increased the sensitivity of C. albicans to caspofungin under planktonic conditions, and may be a sensitizer for caspofungin against C. albicans under planktonic conditions. Our results corroborate these findings and led to the inference that ASA could increase the sensitivity of clinical $C$. albicans and may be used to sensitize this fungus to azole drugs under planktonic conditions.

C. albicans usually exist in the body under two states (planktonic and biofilm). Biofilm is an extracellular polymeric matrix produced by the microbial community for selfprotection that can adhere to the surface of living or nonliving materials. ${ }^{30}$ The biofilm state, a survival mode that differs from the planktonic state, is the organism that adopts to adapt to long-term environmental pressure. ${ }^{31}$ Mature biofilms are a dense mesh system consisting of yeast cells, hyphae, and pseudohyphae surrounded by numerous extracellular polymers. ${ }^{32}$ Additionally, biofilm formation may be correlated with the antimicrobial resistance phenotype. Senobar Tahaei et $\mathrm{al}^{33}$ investigated 300 strains of clinical Staphylococcus aureus and did not find any associations between methicillin resistance and biofilm production, whereas erythromycin, clindamycin, and rifampin resistance were associated with biofilm positivity. These findings indicate that biofilm formation may be a factor leading to C. albicans resistance. A previous study proposed NSAIDs as potential antimicrobials based on their inhibition of quorum sensing in the investigation of drug repurposing strategies for antibacterial and anti-virulence effects. ${ }^{34}$

ASA is an NSAID and to further elucidate its effects on $C$. albicans growth in combination with azole drugs, the biofilms of $C$. albicans were established and the drug $\mathrm{MIC}_{50}$ values were measured. In the current experiment under biofilm conditions, cotreatment with ASA decreased the $\mathrm{MIC}_{50}$ values of FCA, ITR, and VRC from 128 to 8 $\mu \mathrm{g} / \mathrm{mL}$ to $32-0.5 \mu \mathrm{g} / \mathrm{mL}, 32-4 \mu \mathrm{g} / \mathrm{mL}$ to $16-0.5-\mu \mathrm{g} / \mathrm{mL}$, and $32-0.5 \mu \mathrm{g} / \mathrm{mL}$ to $8-0.0625 \mu \mathrm{g} / \mathrm{mL}$, respectively. Based on the FICI results, the rates at which ASA sensitized the fungal strain to FCA, ITR, or FCA under biofilm conditions were $46.15 \%, 46.15 \%$, and $48.72 \%$, respectively. Alem et $\mathrm{al}^{35}$ reported that ASA dramatically inhibited biofilm formation in C. albicans GDH 2346 in a dosedependent manner. At concentrations between $100 \mu \mathrm{M}$ and $1 \mathrm{mM}$, ASA showed a $>70 \%$ inhibition of the biofilm, whereas at concentrations between 50 and $75 \mu \mathrm{M}$, the inhibition was only $20 \%$, and $10 \mu \mathrm{M}$ showed no effect. Zhou et $\mathrm{al}^{36}$ explored the interaction between ASA and amphotericin $\mathrm{B}$ in their activity against $C$. albicans and C. parapsilosis under planktonic and biofilm conditions, and found that ASA enhanced the activity of amphotericin $\mathrm{B}$, and the combination exhibited a strong synergistic effect on $C$. albicans and $C$. parapsilosis under biofilm conditions. Therefore, we speculated that cotreatment with ASA significantly reduced the $\mathrm{MIC}_{50}$ values of FCA, ITR, and VRC and synergized their inhibitory effects on C. albicans under biofilm conditions, thereby further suppressing the growth of $C$. albicans in the biofilm state.

\section{Conclusion}

In conclusion, ASA may serve as a sensitizer for azole drugs to further enhance their inhibition of the growth of clinical C. albicans under planktonic and biofilm conditions. However, the curative effects of the combination of ASA and azole drugs on $C$. albicans should be further verified in vivo, and the underlying mechanisms of action need to be further elucidated. Our findings provide a novel and potential therapeutic strategy for the clinical treatment of candidiasis and a theoretical basis for the use of ASA as a sensitizer for azole drugs in the treatment of $C$. albicans infection.

\section{Data Sharing Statement}

The datasets used and/or analyzed during the current study are available from the corresponding author upon reasonable request.

\section{Acknowledgments}

This study was supported by Research and Development Key Projects of Shanxi Province (Project number: 201903D321123 and 201603D321063), Basic Research Project supported by Shanxi Province (Project number: 201701D121171), Research Project Supported by Health Commission of Shanxi Province (Project number: 201601050 and 2018048), the General Project of the 
National Natural Science Foundation of China (Project number: 82072262), and the $5^{\text {th }}$ of emerging industry leading talent projects in Shanxi Province.

\section{Disclosure}

The authors report no conflicts of interest in this work.

\section{References}

1. von Lilienfeld-toal M, Wagener J, Einsele H, Cornely OA, Kurzai O. Invasive fungal infection. Dtsch Arztebl Int. 2019;116(16):271-278. doi:10.3238/arztebl.2019.0271

2. Gajdacs M, Doczi I, Abrok M, Lazar A, Burian K. Epidemiology of candiduria and Candida urinary tract infections in inpatients and outpatients: results from a 10-year retrospective survey. Cent European J Urol. 2019;72(2):209-214. doi:10.5173/ceju.2019.1909

3. Fu J, Ding Y, Wei B, et al. Epidemiology of Candida albicans and non-C.albicans of neonatal candidemia at a tertiary care hospital in western China. BMC Infect Dis. 2017;17(1):329. doi:10.1186/ s12879-017-2423-8

4. Guinea J. Global trends in the distribution of Candida species causing candidemia. Clin Microbiol Infect. 2014;20(Suppl 6):5-10. doi:10.1111/1469-0691.12539

5. Lamoth F, Lockhart SR, Berkow EL, Calandra T. Changes in the epidemiological landscape of invasive candidiasis. J Antimicrob Chemother. 2018;73(suppl_1):i4-i13. doi:10.1093/jac/dkx444

6. Hani U, Shivakumar HG, Vaghela R, Osmani RA, Shrivastava A. Candidiasis: a fungal infection-current challenges and progress in prevention and treatment. Infect Disord Drug Targets. 2015;15 (1):42-52. doi:10.2174/1871526515666150320162036

7. Katragkou A, McCarthy M, Alexander EL, et al. In vitro interactions between farnesol and fluconazole, amphotericin B or micafungin against Candida albicans biofilms. $J$ Antimicrob Chemother 2015;70(2):470-478. doi:10.1093/jac/dku374

8. Golabek K, Strzelczyk JK, Owczarek A, Cuber P, Slemp-Migiel A, Wiczkowski A. Selected mechanisms of molecular resistance of Candida albicans to azole drugs. Acta Biochim Pol. 2015;62 (2):247-251. doi:10.18388/abp.2014_940

9. Akbari F, Kjellerup BV. Elimination of bloodstream infections associated with Candida albicans biofilm in intravascular catheters. Pathogens. 2015;4(3):457-469. doi:10.3390/pathogens4030457

10. Kim DJ, Lee MW, Choi JS, Lee SG, Park JY, Kim SW. Inhibitory activity of hinokitiol against biofilm formation in fluconazole-resistant Candida species. PLoS One. 2017;12(2): e0171244. doi:10.1371/journal.pone.0171244

11. Noverr MC, Phare SM, Toews GB, Coffey MJ, Huffnagle GB, Kozel TR. Pathogenic yeasts Cryptococcus neoformans and Candida albicans produce immunomodulatory prostaglandins. Infect Immun. 2001;69(5):2957-2963. doi:10.1128/IAI.69.5.29572963.2001

12. Deva R, Ciccoli R, Kock L, Nigam S. Involvement of aspirin-sensitive oxylipins in vulvovaginal candidiasis. FEMS Microbiol Lett. 2001;198(1):37-43. doi:10.1111/j.1574-6968.2001. tb10616.x

13. Madariaga-Venegas F, Fernandez-Soto R, Duarte LF, et al. Characterization of a novel antibiofilm effect of nitric oxide-releasing aspirin (NCX-4040) on Candida albicans isolates from denture stomatitis patients. PLoS One. 2017;12(5):e0176755. doi:10.1371/journal.pone. 0176755

14. Rusu E, Radu-Popescu M, Pelinescu D, Vassu T. Treatment with some anti-inflammatory drugs reduces germ tube formation in Candida albicans strains. Braz J Microbiol. 2014;45(4):1379-1383. doi:10.1590/s1517-83822014000400031
15. Ogundeji AO, Pohl $\mathrm{CH}$, Sebolai OM. Repurposing of aspirin and ibuprofen as candidate anti-cryptococcus drugs. Antimicrob Agents Chemother. 2016;60(8):4799-4808. doi:10.1128/AAC.02810-15

16. Silva NC, JsM N, Dias ALT. Aspartic proteinases of Candida spp.: role in pathogenicity and antifungal resistance. Mycoses. 2013;57 (1):1-11. doi:10.1111/myc.12095

17. Chen S, Xia J, Li C, Zuo L, Wei X. The possible molecular mechanisms of farnesol on the antifungal resistance of C. albicans biofilms: the regulation of CYR1 and PDE2. BMC Microbiol. 2018;18(1):203. doi:10.1186/s12866-018-1344-Z

18. Hawser SP, Baillie GS, Douglas LJ. Production of extracellular matrix by Candida albicans biofilms. J Med Microbiol. 1998;47 (3):253-256. doi:10.1099/00222615-47-3-253

19. Feng W, Yang J, Yang L, et al. Research of Mrr1, Cap1 and MDR1 in Candida albicans resistant to azole medications. Exp Ther Med. 2018;15(2):1217-1224. doi:10.3892/etm.2017.5518

20. Feng W, Yang J, Ji Y, et al. Mrr2 mutations and upregulation are associated with increased fluconazole resistance in Candida albicans isolates from patients with vulvovaginal candidiasis. Lett Appl Microbiol. 2020;70(2):95-101. doi:10.1111/lam.13248

21. Shi C, Liu J, Li W, Zhao Y, Meng L, Xiang M. Expression of fluconazole resistance-associated genes in biofilm from 23 clinical isolates of Candida albicans. Braz J Microbiol. 2019;50(1):157-163. doi:10.1007/s42770-018-0009-2

22. Tamura T, Asahara M, Yamamoto M, et al. In vitro susceptibility of dermatomycoses agents to six antifungal drugs and evaluation by fractional inhibitory concentration index of combined effects of amorolfine and itraconazole in dermatophytes. Microbiol Immunol. 2014;58(1):1-8. doi:10.1111/1348-0421.12109

23. Odds FC. Synergy, antagonism, and what the chequerboard puts between them. J Antimicrob Chemother. 2003;52(1):1. doi:10.1093/ jac/dkg301

24. Feng W, Yang J, Ma Y, et al. Aspirin and verapamil increase the sensitivity of Candida albicans to caspofungin under planktonic and biofilm conditions. J Glob Antimicrob Resist. 2021;24:32-39. doi:10.1016/j.jgar.2020.11.013

25. Zhang L, Lin H, Liu W, et al. Antifungal activity of the ethanol extract from flos rosae chinensis with activity against fluconazole-resistant clinical Candida. Evid Based Complement Alternat Med. 2017;2017:4780746. doi:10.1155/2017/4780746

26. Ahangarkani F, Khodavaisy S, Mahmoudi S, et al. Indifferent effect of nonsteroidal anti-inflammatory drugs (NSAIDs) combined with fluconazole against multidrug-resistant Candida auris. Curr Med Mycol. 2019;5(3):26-30. doi:10.18502/cmm.5.3.1743

27. Krol J, Nawrot U, Bartoszewicz M. Anti-candidal activity of selected analgesic drugs used alone and in combination with fluconazole, itraconazole, voriconazole, posaconazole and isavuconazole. $J$ Mycol Med. 2018;28(2):327-331. doi:10.1016/j.mycmed.2018.03.002

28. Pina-Vaz C, Sansonetty F, Rodrigues AG, Martinez DEOJ, Fonseca AF, Mardh PA. Antifungal activity of ibuprofen alone and in combination with fluconazole against Candida species. $\mathrm{J} \mathrm{Med}$ Microbiol. 2000;49(9):831-840. doi:10.1099/0022-1317-49-9-831

29. Scott EM, Tariq VN, McCrory RM. Demonstration of synergy with fluconazole and either ibuprofen, sodium salicylate, or propylparaben against Candida albicans in vitro. Antimicrob Agents Chemother. 1995;39(12):2610-2614. doi:10.1128/aac.39.12.2610

30. Mitchell KF, Zarnowski R, Sanchez H, et al. Community participation in biofilm matrix assembly and function. Proc Natl Acad Sci U S A. 2015;112(13):4092-4097. doi:10.1073/pnas.1421437112

31. Blankenship JR, Mitchell AP. How to build a biofilm: a fungal perspective. Curr Opin Microbiol. 2006;9(6):588-594. doi:10.1016/ j.mib.2006.10.003

32. Tan Y, Leonhard M, Ma S, Schneider-Stickler B. Influence of culture conditions for clinically isolated non-albicans Candida biofilm formation. J Microbiol Methods. 2016;130:123-128. doi:10.1016/j. mimet.2016.09.011 
33. Senobar Tahaei SA, Stájer A, Barrak I, Ostorházi E, Szabó D, Gajdács M. Correlation between biofilm-formation and the antibiotic resistant phenotype in staphylococcus aureus isolates: a Laboratory-Based Study in Hungary and a review of the literature. Infect Drug Resist. 2021;14:1155-1168. doi:10.2147/idr.S303992

34. Gajdacs M, Spengler G. The role of drug repurposing in the development of novel antimicrobial drugs: non-antibiotic pharmacological agents as quorum sensing-inhibitors. Antibiotics (Basel). 2019;8(4). doi:10.3390/antibiotics 8040270
35. Alem MA, Douglas LJ. Effects of aspirin and other nonsteroidal anti-inflammatory drugs on biofilms and planktonic cells of Candida albicans. Antimicrob Agents Chemother. 2004;48(1):41-47. doi:10.1128/aac.48.1.41-47.2004

36. Zhou Y, Wang G, Li Y, et al. In vitro interactions between aspirin and amphotericin B against planktonic cells and biofilm cells of Candida albicans and C. parapsilosis. Antimicrob Agents Chemother. 2012;56 (6):3250-3260. doi:10.1128/AAC.06082-11

\section{Publish your work in this journal}

Infection and Drug Resistance is an international, peer-reviewed openaccess journal that focuses on the optimal treatment of infection (bacterial, fungal and viral) and the development and institution of preventive strategies to minimize the development and spread of resistance. The journal is specifically concerned with the epidemiology of antibiotic resistance and the mechanisms of resistance development and diffusion in both hospitals and the community. The manuscript management system is completely online and includes a very quick and fair peerreview system, which is all easy to use. Visit http://www.dovepress.com/ testimonials.php to read real quotes from published authors. 